\title{
The molecular basis of memory. Part 3: tagging with "emotive" neurotransmitters
}

\author{
Gerard Marx ${ }^{1}$ and Chaim Gilon ${ }^{2 *}$ \\ MX Biotech Ltd., Jerusalem, Israel \\ ${ }^{2}$ Department of Organic Chemistry, Institute of Chemistry, Hebrew University, Jerusalem, Israel
}

\section{Edited by:}

Paul Adlard, The Mental Health

Research Institute, Australia

Reviewed by:

Craig Atwood, University of

Wisconsin, USA

Sason Shaik, The Hebrew

University, Israel

*Correspondence:

Chaim Gilon, Department of Organic Chemistry, Institute of Chemistry,

Hebrew University, Givaat Ram,

Jerusalem 91904, Israel

e-mail: chaimgilon@gmail.com
Many neurons of all animals that exhibit memory (snails, worms, flies, vertebrae) present arborized shapes with many varicosities and boutons. These neurons, release neurotransmitters and contain ionotropic receptors that produce and sense electrical signals (ephaptic transmission). The extended shapes maximize neural contact with the surrounding neutrix [defined as: neural extracellular matrix $(n E C M)+$ diffusible (neurometals and neurotransmitters)] as well as with other neurons. We propose a tripartite mechanism of animal memory based on the dynamic interactions of splayed neurons with the "neutrix." Their interactions form cognitive units of information (cuinfo), metal-centered complexes within the $\mathrm{nECM}$ around the neuron. Emotive content is provided by NTs, which embody molecular links between physiologic (body) responses and psychic feelings. We propose that neurotransmitters form mixed complexes with cuinfo used for tagging emotive memory. Thus, NTs provide encoding option not available to a Turing, binary-based, device. The neurons employ combinatorially diverse options, with >10 NMs and >90 NTs for encoding ("flavoring") cuinfo with emotive tags. The neural network efficiently encodes, decodes and consolidates related (entangled) sets of cuinfo into a coherent pattern, the basis for emotionally imbued memory, critical for determining a behavioral choice aimed at survival. The tripartite mechanism with tagging of NTs permits of a causal connection between physiology and psychology.

Keywords: metal complex, cuinfo, neurotransmitters, emotion, mentation

\section{INTRODUCTION}

The neural circuitry of the brain has been likened to a biological computing device. But the process whereby a physiologic process (stimulus sensation) transforms into a psychical sensation (such as emotionally-tinged memory), which determines physical response to immediate stimuli, remains mysterious (Figure 1).

Each of the senses receives environmental stimuli (input) which are transformed into a synaptic cognitive information (cog-info) signals, which are somehow encoded and stored somewhere in the brain, later to be decoded (recalled), to determine a behavioral choice based on recalled experience. Much has been speculated in philosophical term (Romanes, 1883; James, 1884; Langer, 1967; Meshulam et al., 2011) and on the basis of biologic observations (Squire and Kandel, 2008; Kandel, 2009; GarciaLopez1 et al., 2010; DeFelipe, 2011; Murtya et al., 2011; Emmons, 2012; Jarrell et al., 2012; Hirano et al., 2013; Strausfeld and Hirth, 2013; Wright et al., 2013), but molecular details for the mentation of memory by neural animals are lacking.

Q: Does the brain operate like a Turing machine (Boole, 1853; Turing, 1950)?

A: Computer and machine circuits (Figure 2A) operate in dry condition. Wires in an electric circuit are insulated from one another by plastic, non-conducting, coatings and air gaps (or vacuum), to prevent short circuits.

By contrast, we previously pointed out that neurons are enclothed in a wet, electrically conducting hydrogel (nECM) with many component glycosaminoglycans (GAGs) and proteins (Marx and Gilon, 2012, 2013). The intimate contacts of the extended neural surface with the nECM permits iontophoretic/piezo-electric/visco-elastic actuators on the neural surface to metamorph cog-info into cuinfo. Images of "naked" neurons suspended in vacuous space are misleading, in that they ignore the nECM and the dopants (NTs and neurometals) distributed therein. Cajal did not perceive their roles in neural mentation (Figure 2B; see Garcia-Lopez1 et al., 2010). Rather, the intuitive painting of Pollock (1997) more closely represents the physical circumstances of neurons enclothed within a biogel lattice (Figure 2C).

\section{ENCODING EMOTIONS}

Neural memory recalls emotive as well as objective qualities. As conceived by the philosopher William James and other philosophers (Romanes, 1883; James, 1884; Langer, 1967; Meshulam et al., 2011), emotions have physical correlates.

Q: What kind of molecular structure or process endows memory with emotive quality?

A: Possibly, neurotransmitters (NTs) are involved. They eliciting a range of physiologic and psychic responses and most of them bind to metals.

We point out that the NTs are a class of molecules synthesized and secreted by neurons that elicit emotive reactions, 
concomitant with physiologic responses. Thus, NTs can be considered as the molecular embodiments of emotions. In that they have strong affinity to metals, they can form ternary complexes with metals, as exemplified by the binding of bilirubin to albumin (Marx, 1984). We propose that the NTs (Hughes and Zubek, 1956; Colburn and Maas, 1965; Boggess and Martin, 1975; Chandra et al., 1980; Ludlam et al., 1980; Sigel and Martin, 1982; Jolles, 1983; Coffman and Dunn, 1988; Flood et al., 1990; Jefferys, 1995; Velez-Pardo et al., 1995; White and Rumbold, 1988; Buhot et al., 2000; Reith, 2002; Shaik, 2003; Álvarez and Ruarte, 2004; Siegel et al., 2005; Kroval et al., 2006; Marazziti et al., 2006; Neumann, 2007; Wyttenbach et al., 2008; Paoletti et al., 2009; van der Burgt et al., 2009; Burbach, 2010; Dere et al., 2010; Guastella et al., 2010; Brady et al., 2011; Lesburguères et al., 2011; Beets et al., 2012; García et al., 2012; Garrison et al., 2012; Ma et al., 2013; Pitt et al., 2013; Yanagita et al., 2013) provide the neural net with a new mode of processing (mentating) cognitive information (cog-info) not available to a binary Turing machine.

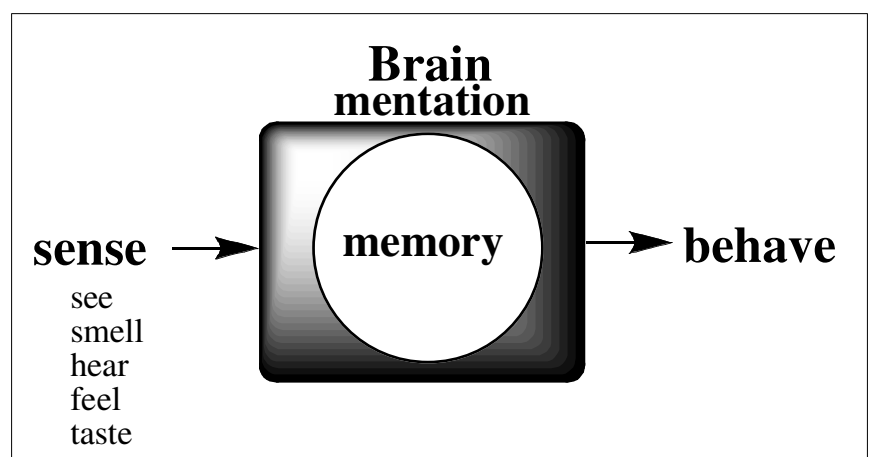

FIGURE 1 | Schematic of the process whereby an external stimulus is remembered to determine whole body response, critical for survival.

\section{TRIPARTITE MECHANISM}

To rationalize the phenomenon of biologic memory in physicalchemical terms, we have proposed (Marx and Gilon, 2012, 2013) a tripartite mechanism comprising 3 physiologic compartments:

- Neuron-elongated cell in synaptic and non-synaptic contact with others

- nECM-an anionic biogel lattice surrounding the neuron

- dopants-neurometals and neurotransmitters (NTs) - metals (e.g., $\mathrm{Al}^{+3}, \mathrm{Ca}^{+2}, \mathrm{Co}^{+2}, \mathrm{Cu}^{+2}, \mathrm{Fe}^{+2 / 3}, \mathrm{Mg}^{+2}, \mathrm{Mn}^{+2 / 3}, \mathrm{Zn}^{+2}$ ) and small molecular modulators, distributed in the nECM.

Though the term "space" is often used to refer to the neurons' environment, it is not quite correct. The neurons are not naked, floating in space. Rather, they are suspended (enmeshed) in a matrix composed of glycosamino-glycans (GAGs) and proteins (such as tenascins, and laminin), referred to as "nECM." Their shape (highly elongated with many dendrites, splayed, arborized) exposes the large surface to intimate contact with the nECM, through which chemical, as well as electrical, signaling occur.

Just like all other physiologic processes, mentation must be biochemically based. All three of the above compartments are involved in transforming (encoding) cognitive information (coginfo) incoming from the senses, into [nECM:metal] complexes, the molecular correlates of cognitive units of information (cuinfo), like computer bits. The incoming cog-info is transferred to the brain via into synaptic and non-synaptic networks. But what happens there?

We generalize a biochemical processes and notations, which feature sets of metal-centered complexes (cuinfo) which can undergo different types of redox, tagging and cross-linking reactions, thereby modulating the dielectric properties, viscoelasticity and stability of local, molecular ensembles. The neuron is atuned to such nECM ensembles and can thereby chemically affect/sense (encode/decode) cog-info.
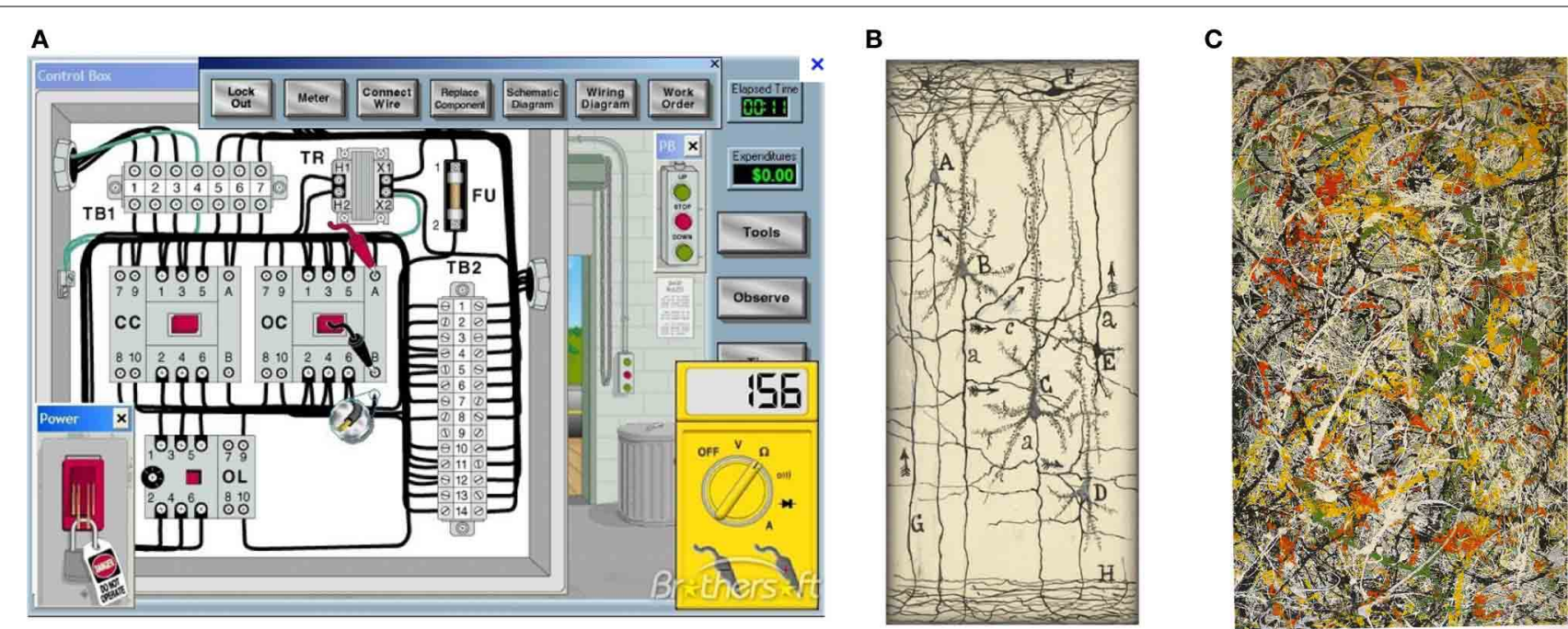

FIGURE 2 | (A) Circuit for electric motor. (Note the insulating spaces between wires and components). (B) Cajal drawing of a neural circuit (from Garcia-Lopez1 et al., 2010; DeFelipe, 2011). (Note the empty spaces around neurons) (with permission). (C) Painting by Jackson Pollok (Boole, 1853) that more closely represents neurons enmeshed within the nECM. (No empty spaces). (with permission). 
Table 1 | Metal complexing neurotransmitters.

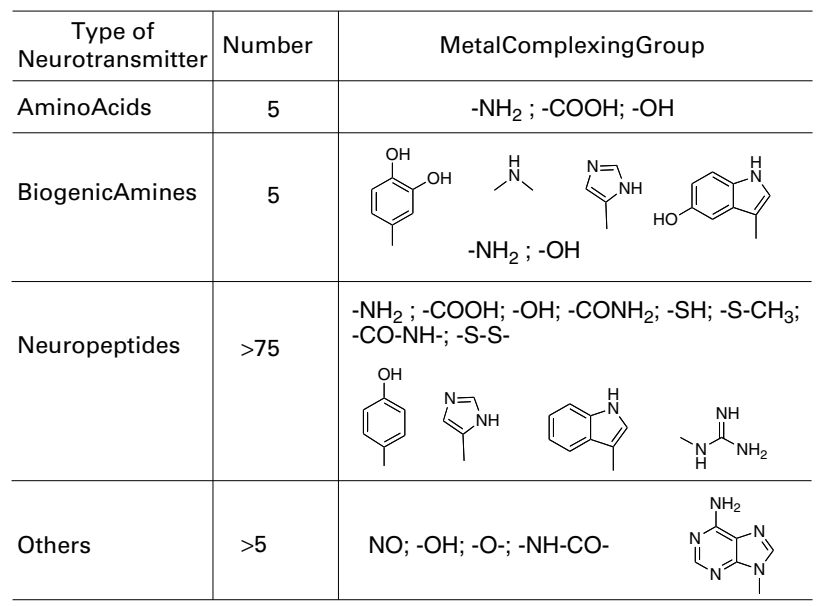

Types and structures (Hughes and Zubek, 1956; Colburn and Maas, 1965; Boggess and Martin, 1975; Chandra et al., 1980; Ludlam et al., 1980; Sigel and Martin, 1982; Jolles, 1983; Coffman and Dunn, 1988; Flood et al., 1990; Jefferys, 1995; Velez-Pardo et al., 1995; White and Rumbold, 1988; Buhot et al., 2000; Reith, 2002; Shaik, 2003; Álvarez and Ruarte, 2004; Siegel et al., 2005; Kroval et al., 2006; Marazziti et al., 2006; Neumann, 2007; Wyttenbach et al., 2008; Paoletti et al., 2009; van der Burgt et al., 2009; Burbach, 2010; Dere et al., 2010; Guastella et al., 2010; Brady et al., 2011; Lesburguères et al., 2011; Beets et al., 2012; García et al., 2012; Garrison et al., 2012; Ma et al., 2013; Pitt et al., 2013; Yanagita et al., 2013).

Focusing on the neurotransmitters (NTs) shown in Table 1, all present a variety of metal complexing moieties called ligands (e.g., glycine, glutamate catechol amines, neuropeptides, adenosine) that can form mixed complexes with cuinfo. Activated neurons release vesicles containing NTs along with neurometals $\left(\mathrm{M}^{+v}\right.$; such as $\mathrm{Ca}^{+2,} \mathrm{Cu}^{+2}, \mathrm{Fe}^{+3,} \mathrm{Mn}^{+2}, \mathrm{Zn}^{+2}$, etc.) into the $\mathrm{nECM}$ of the synaptic cleft and other extracellular locations, permitting the formation of ternary complexes [nECM: $\mathrm{M}^{+\mathrm{v}}$ :NT]. Some larger one permit coordination with more than 1 metal centered cuinfo (bidendate, tridendate).

With the exception of acetylcholine and muscarine, which are true cationic entities due to their tetrasubstituted ammonium moiety, most NTs are electron donors, behaving as effective metal complexants (ligands) (Table 1). An individual NT can be considered to embody an "emotive" signal, if it elicits physiologic responses (pulse, breathing, dilation of blood vessels and pupil, erection, sweating, etc), as well as corresponding psychic reactions (attention, anxiety, anger, fear, hunger, pain, love, etc.), which are remembered. Chemically, an electron-rich NT molecule diffusing in the nECM can bind to a metalcentered cuinfo, confers an emotive tag to the ternary (mixed) complex, resulting in a tagged, cuinfo:NT. The stability of such complexes depends on the valency of the metal cation and binding affinity of the components $\left(\mathrm{pK}_{\mathrm{D}}\right)$. Monovalent metal $\left(\mathrm{Na}^{+}, \mathrm{K}^{+}, \mathrm{Li}^{+}, \mathrm{Cs}^{+}\right)$complexes are relatively unstable; the resultant cuinfo tend to rapidly disintegrate. Small monodendate NTs bind to a single cuinfo; larger ones are polydendate and could bind to multiple cuinfo, thereby literally "entangling" them. Table 2 below organizes the metal-complexing NT which have been shown to induce physiologically-linked
Table 2 | Bio-modulators (also called NTs) of physiologic responses to stimuli, which simultaneously elicit both physiologic responses and psychic (emotions) feelings, which also encode the stimuli, aiding the recall (memory).

\begin{tabular}{|c|c|c|c|}
\hline $\begin{array}{l}\text { Modulators } \\
\text { (neurotransmitters) }\end{array}$ & $\begin{array}{l}\text { Metal } \\
\text { complexing } \\
\text { ligands }\end{array}$ & $\begin{array}{l}\text { Physiologic } \\
\text { reactions }\end{array}$ & $\begin{array}{l}\text { Psychic } \\
\text { effects } \\
\text { emotions }\end{array}$ \\
\hline $\begin{array}{l}\text { Acetylcholine (AcChol) } \\
\text { Epinephrine (EPI) } \\
\text { Serotonin (SER) } \\
\text { Histamine (HIS) } \\
\text { Nicotine } \\
\text { Muscarine } \\
\text { Amino acids } \\
>75 \text { neuropeptides }\end{array}$ & $\begin{array}{l}\text { NO } \\
\text { YES } \\
\text { YES } \\
\text { YES } \\
\text { YES } \\
\text { NO } \\
\text { YES } \\
\text { YES }\end{array}$ & $\begin{array}{l}\text { Breathing } \\
\text { Blinking } \\
\text { Blood pressure } \\
\text { Coughing } \\
\text { Crying } \\
\text { Dilation of pupil } \\
\text { Drooling } \\
\text { Erection } \\
\text { Evacuation } \\
\text { Fever } \\
\text { Goose-bumps } \\
\text { Heart beat } \\
\text { Itching } \\
\text { Orgasm } \\
\text { Pulse } \\
\text { Salivation } \\
\text { Secretion } \\
\text { Spasms } \\
\text { Sweating } \\
\text { Tremors } \\
\text { Urination } \\
\text { Vasodilation } \\
\text { Vomiting }\end{array}$ & $\begin{array}{l}\text { Anxiety } \\
\text { Aggression } \\
\text { Awareness } \\
\text { Depression } \\
\text { Fear } \\
\text { Hate } \\
\text { Heat } \\
\text { Hunger } \\
\text { Joy } \\
\text { Love } \\
\text { Pain } \\
\text { Sadness } \\
\text { Sex drive }\end{array}$ \\
\hline
\end{tabular}

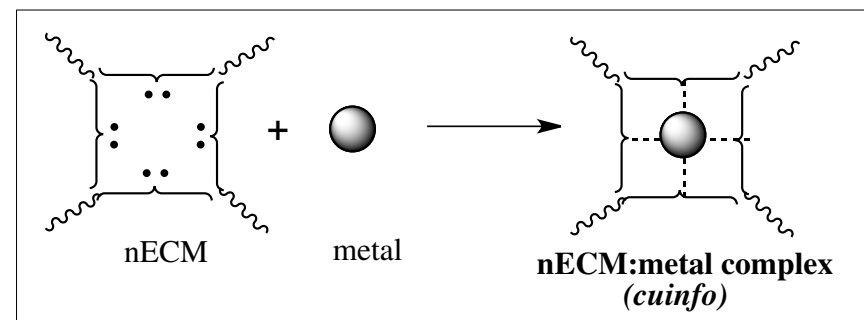

FIGURE 3 | Iconographic representation of formation of anECM:metal complex (cuinfo). The chelating node (address) within the $\mathrm{nECM}$ is presented as square electron-rich hole fixed within the nECM lattice, with 2 dots representing ligands available for capturing a metal. The metal-bonded to the complexing group electrons is indicated by a dotted line, within the cuinfo. It can serve as a binding focus for metabolites and

neurotransmitters. The nECM array with metal complexes is called neutrix.

psychic responses to stimuli (Table 2), are also imprinted in memory.

\section{ICONOGRAPHY}

We offer an iconography to visualize the formation of cuinfo (Figure 3) and their transformation by tagging with NT (Figure 4). To stay within the IUPAC guidelines for chemical notations, the graphic notation previously employed has been slightly modified (Boole, 1853; Marx and Gilon, 2012, 2013). The complexing moieties (ligands) in the nECM are presented as two dots (non-bonding pair of electrons). The metal bonded to the 


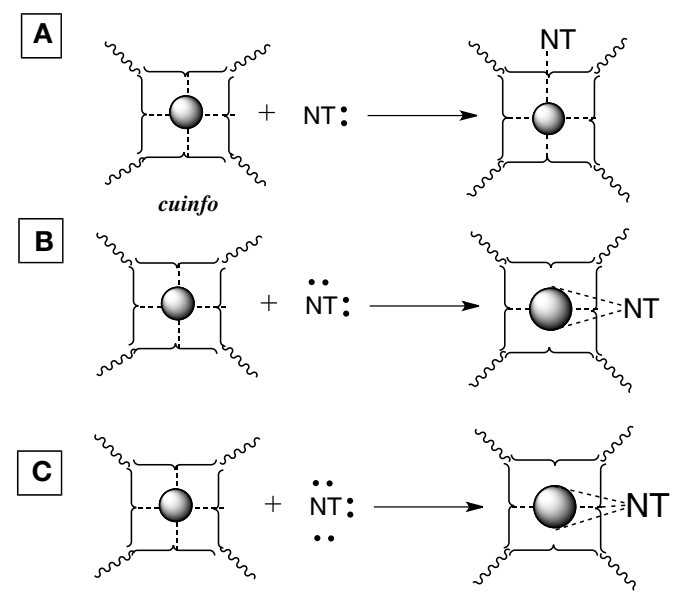

FIGURE 4 | Various types of [cuinfo:NT] complexes. (A) A monodentate NT replaces one neutrix metal bond. (B) A bidentate NT couples (entangles) 2 cuinfo. (C) A tridentate NT replaces three neutrix metal bonds. (D) A
D

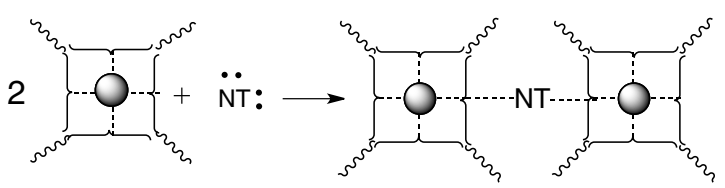

$\mathbf{E}$

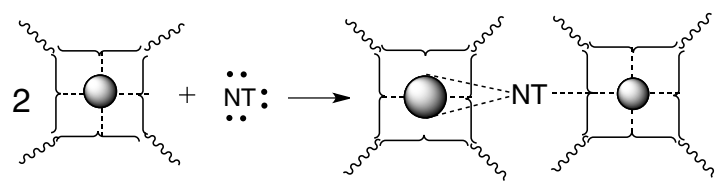

$\mathbf{F}$

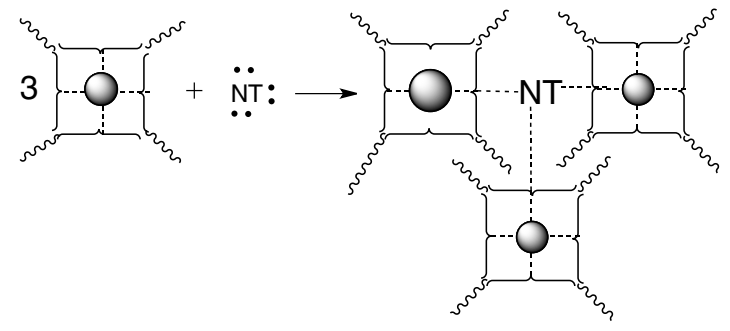

bidentate NT entangles two cuinfo. (E) A tridentate NT entangles two cuinfo, via double and single complexing bonds. (F) A tridentate NT entangles three cuinfo. complexing groups in the nECM is indicated by a dotted line (e.g., Figure 3). We have defined an arbitrary unit of cognitive information as cuinfo. We call the nECM array with metal complexes: neutrix.

\section{EXAMPLES OF METAL CHELATING NEUROTRANSMITTERS (NTs)}

The NT can be considered to embody "emotive" signals, in that they elicit emotive physiologic reactions (attention, anxiety, anger, fear, love, pain, etc) that are remembered. Many NT are also effective metal chelators. Chemically, the presence of an NT can "flavor" a cuinfo. The resultant ternary complex is more stable, crowned with an emotive tag. Such chelate complexes are reversible depending on their binding strength to a particular cuinfo $\left(\mathrm{pK}_{\mathrm{D}}\right)$. Some redox and crosslinking reaction can stabilize these.

Mono-, bi- and tridentate complexes of electron-rich NTs with metal-centered cuinfo can be conceived (Figure 4). In such mixed complexes, the NT replaces one or more neutrix metal bond also indicated by a dotted line

Of course, cross-linking (from either redox or enzymatic) reactions would render the entire ensemble much more stable, relevant to long term memory.

\section{TYPES OF NTS}

A: Catecholamines: epinephrine (EPI), norepinephrine (NE), dopamine (DA) (Colburn and Maas, 1965; Boggess and Martin, 1975; Chandra et al., 1980; Kroval et al., 2006; García et al., 2012).

Catecholamines are "emotive" neurotransmitters associated with fear, fright, anxiety, all emotions strongly recalled in memory. Physiologically, they elicit responses such an altered heart rate, blood flow, pupil dilation, muscle contraction, etc. Chemically, they comprise an ortho-dihydroxy benzene structure, a potent metal chelating moiety; stored within neuron's vesicles and released upon signaling. The NT of this class, the dopamine (DA), norepinephrine (NE) and epinephrine (EPI) can form ternary complexes with cuinfo, generaly described in Figure 6.

The catecholamines present 2 independent chelate centers (the ortho hydroxy benzene and the distal amino terminus) which can bridge two adjacent cuinfo, effectively entangling a pair of cuinfo, rendering them more stable as well as more identifiable (tagging) for linked (entangled) recall. They permit of emotive memory associated with physiologic reactions.

B: Amino acids (Hughes and Zubek, 1956; White and Rumbold, 1988; Flood et al., 1990; Velez-Pardo et al., 1995; Buhot et al., 2000; Álvarez and Ruarte, 2004; Siegel et al., 2005; Paoletti et al., 2009; Dere et al., 2010; Lesburguères et al., 2011) and other small molecules.

In the same manner, other NT such as glutamine, histidine, and seratonin, which affect numerous physiologic responses (water balance, immune reactions, blood clotting, fever, sweating), as well as emotion, can form mixed complexes with cuinfo. A lineup of some NT's capable of adorning the cuinfo by chelate complexation is iconographically presented in Figure 7.

C: Metal chelating neuropeptides (Jolles, 1983; Ludlam et al., 1980; Coffman and Dunn, 1988; Marazziti et al., 2006; 


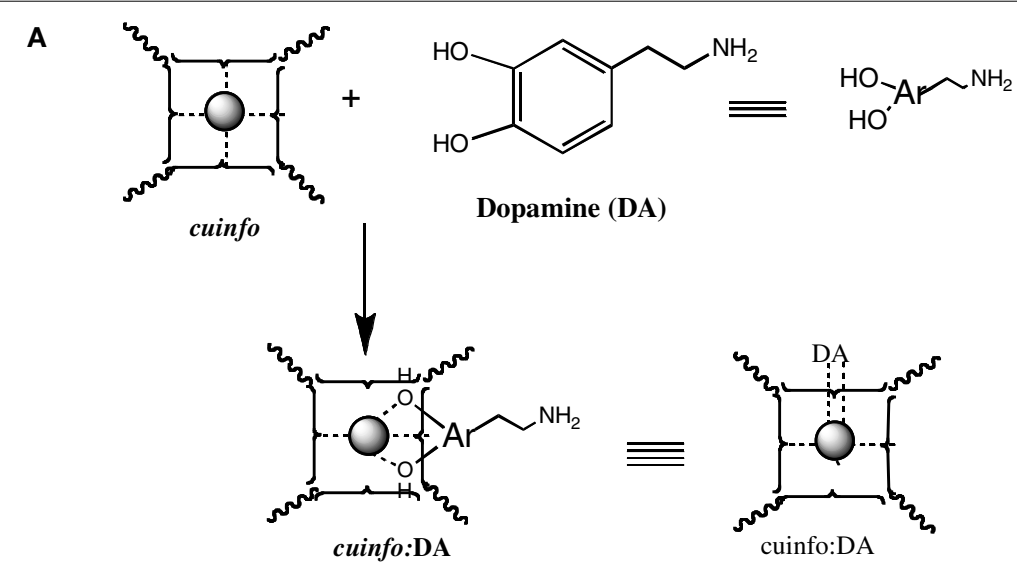

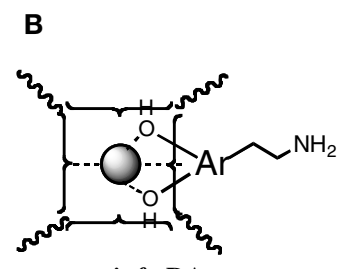

cuinfo:DA

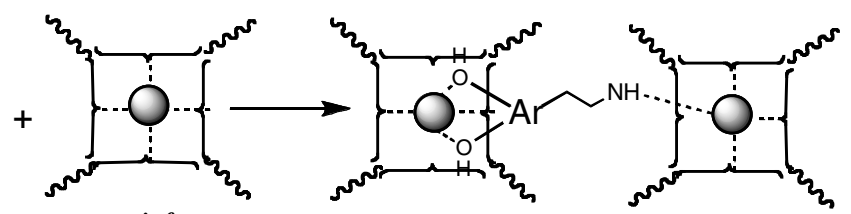

cuinfo

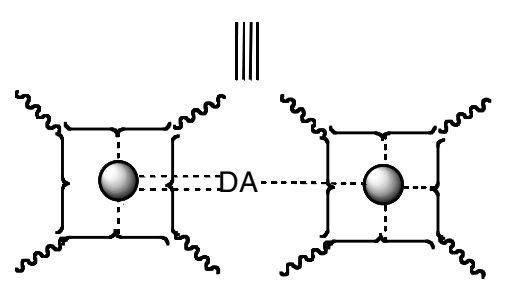

cuinfo:DA:cuinfo

FIGURE 5 | Formation of mixed dopamine:cuinfo complexes. (A) Formation of ternary cuinfo complex with one catecholamine. (B) Formation of a entangled dopamine (DA) complex (cuinfo 2 :DA).

Neumann, 2007; Wyttenbach et al., 2008; van der Burgt et al., 2009; Guastella et al., 2010; Beets et al., 2012; Garrison et al., 2012; Pitt et al., 2013).

Neuropeptides are an important class of molecular communicators in the central and peripheral nervous systems, acting as neurotransmitters, neuromodulators, and hormones. They also connect the nervous system to other physiological networks regulating breathing, pulse, etc. Many neuropeptides are abundantly expressed in brain regions involved in emotional processing and anxiety behaviors.

Neurotransmitters (NTs) and neuropeptides (NP), having various physiological effects have also been implicated in cognitive functions such as learning and memory. The peptides include corticotropin releasing factor, urocortin, neuropeptide $\mathrm{Y}$, vasoactive intestinal polypeptide, neurotensin, galanin, opioid peptides, tachykinins, nociceptin, oxytocin, vasopressin, and angiotensin. In addition to their many physiological functions, NTs elicit psychic effects on mood (anxiety and depression) and memory.

For example oxytocin is cyclic nona-peptides (9 aa), capable of eliciting numerous physiological responses [lactation, blood

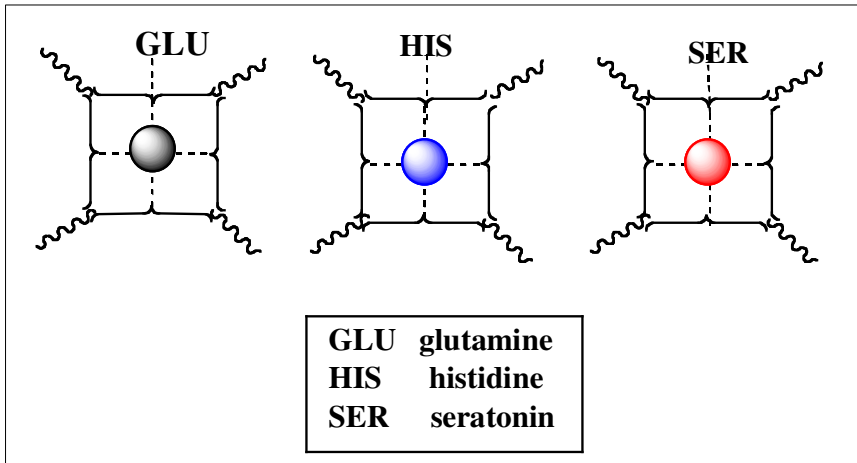

FIGURE 6 | Icons of cuinfo tagged with various neurotransmitters, as ternary complexes.

coagulation (factor VIII)]. It also affects cognitive functions related to memory as well as to emotions love, mood, appetite, sexual behavior, social behavior. The 3-D structure of complexes of oxytocin with $\mathrm{Cu}^{+2}$ and $\mathrm{Zn}^{+2}$ and insulin have been described. For example, the groups in oxytocin, which participates in the 


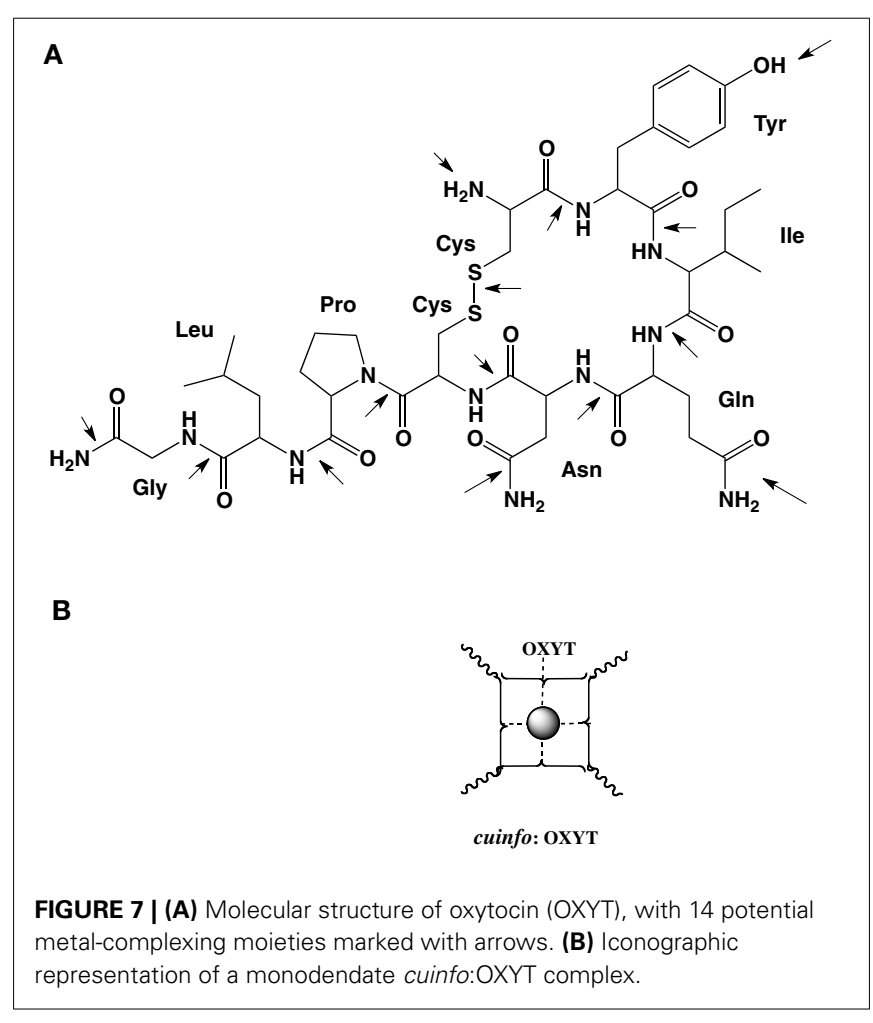

formation of these complexes can also permit the formation of mixed metal complexes with cuinfo. The metal complexing moieties (indicated be arrows in Figure 7) include: the amino terminal Cys ${ }^{1}$ group, the disulfide bond between Cys ${ }^{1}$ and Cys ${ }^{6}$, the phenol group of $\mathrm{Tyr}^{2}$, the carboxamide groups of $\mathrm{Gln}^{4}$ and $\mathrm{Asn}^{5}$, and the terminal carboxamide group of Gly ${ }^{9}$. In addition the peptide bonds constitute multiple metal bonding ligands.

A set of cuinfo might be represented as adjacent units adorned by redox or NT tags.

\section{DISCUSSION}

Memory is a mental function that permits recall of past events, to guide future behavior. One could say: "No cognition without memory." How are different memories assigned value or significance? What are the molecular-scale details? What are the molecular encoders of emotions or feeling (James, 1884; Langer, 1967)?

We point out that the NTs elicit not only physiologic effects but concommitantly elicit psychic effects described as emotions (see Table 2). For the purposes of discussing memory, the NTs can be considered to be the encoders of emotions. With the exception of acetylcholine and muscarine, which both express a tetrasubstituted ammonium moiety and are true cations regardless of the $\mathrm{pH}$, the other NTs are all electron donors, capable of forming ternary, metal-centered complexes, described as cuinfo:NT.

Consider the computer using binary code. Each bit is anonymous, (100111001110), exhibiting no flavor, color, value or priority, one over the other. The Turing machine computes (performs a series of discrete procedures) inexorably according to the laws of logic, mathematics and communication theory, with no emotional context (Boole, 1853; Turing, 1950) or survival import. The

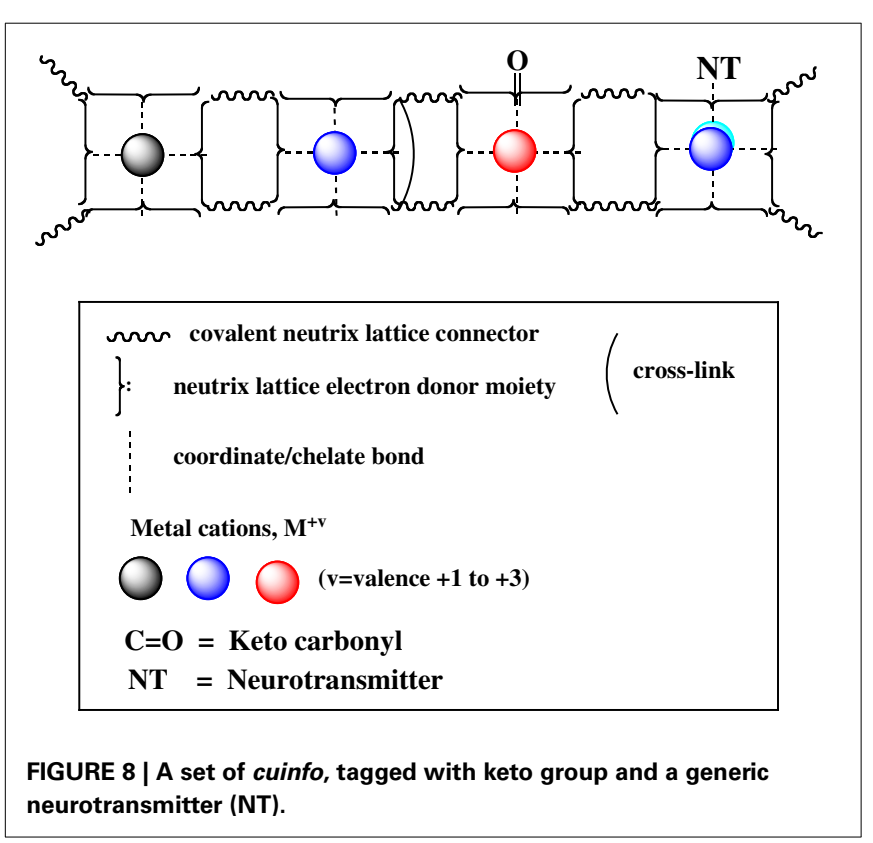

NTs provide the neural system with a novel encoding modality that is missing in binary codes, the emotive option for encoding cog-info, critical for providing value and significance to the memory consolidated from tagged cuinfo:NT, aiding survival.

The brain is first and foremost an emotive organ, mentating emotionally with combinatorially large sets of chemical "encoders" (Lehn, 2002, 2012) to ensure survival. Emotions such as fear, anger, love, etc., drive behavior, are the "coins of significance," which provide a priority value to cog-info, are strongly remembered.

We may not be able to penetrate the realm of subjective experience, but we can describe the molecular correlates and chemical dispositions of psychical processes (mentation) of which memory is an example. The molecular correlates of emotions could be considered to be encoded by NTs (Tables 1,2 ), relatively small molecules that are secreted into the nECM by activated neurons, as part of non-synaptic "chemical signaling" (volume transmission) (Wu et al., 2004; Delgado et al., 2006; Ortega et al., 2007; Syková and Nicholson, 2008; Adlard et al., 2010; Vizi et al., 2010; Kaler, 2011; Sadiq et al., 2012; Trueta and De-Miguel, 2012; Goyal and Chaudhury, 2013; Vizi, 2013). Vesicles containing psychoactive neurometals ( $\mathrm{Al}, \mathrm{Ca}, \mathrm{Co}, \mathrm{Cu}, \mathrm{Fe}, \mathrm{Mg}, \mathrm{Mn}, \mathrm{Zn}$ ) are also released by the neuron into the nECM upon firing, combinatorially encoding cog-info as cuinfo, ternary (mixed) complexes capable of combing with NTs, described by the iconographic notations in Figures 4-8.

Emotion without memory to guide behavior would be very short-lived... the organism would not long survive. Emotions provide value/priority to (incoming) sensorial cog-info. Emotion and memory are functionally linked phenomena... providing motivational significance (value) to guide adaptive behavior. Emotions could be considered as responses that "flavor" cog-info with value, to aid recall and guide behavior.

All animals need to respond emotionally to a specific circumstance, and to remember the specific situation within the 
limitations of its evolved capabilities to recall. The NTs are capable of eliciting both physiologic and psychic responses to a significant experience. Thus, they can affect behavior and also imprint cuinfo with emotive tags, to enable "prioritized recall," enabling survival. The above-described tripartite mechanism with NTs, brings emotion-laden mental sensibility into the compass of biochemical fact, applicable to all neural creatures exhibiting memory.

\section{ACKNOWLEDGMENTS}

By Gerard Marx: In memorium to my late wife and earliest collaborator, the artist Georgette Batlle (1940-2009), from whom I learned graphic sensibility. Thanks to friends Lilly Rivlin (New York) and the late Bill Needle (Eastchester, NY) for early encouragement and financial support in the period 1981-1984. Special thanks to Prof. Randy Gallistel (Rutgers University) and Prof. Tamar Zelniker (TAU) who suggested that we attenuate our focus to "memory," rather than the much broader field of cognition/thought. We have no conflict of interest but are looking for academic and commercial collaborators, notably to develop instrumentation relevant to monitoring trace element distribution in the brain.

\section{REFERENCES}

Adlard, P. A., Parncutt, J. M., Finkelstein, D. I., and Bush, A. I. (2010). Cognitive loss in zinc transporter-3 knock-out mice: a phenocopy for the synaptic and memory deficits of Alzheimer's disease? J. Neurosci. 30, 1631-1636. doi: 10.1523/JNEUROSCI.5255-09.2010

Álvarez, E. O., and Ruarte, M. B. (2004). Glutamic acid and histamine-sensitive neurons in the ventral hippocampus and the basolateral amygdala of the rat: functional interaction on memory and learning processes. Behav. Brain Res. 152, 209-219. doi: 10.1016/j.bbr.2003.10.012

Beets, I., Janssen, T., Meelkop, E., Temmerman, L., Suetens, N., Rademakers, S., et al. (2012). Vasopressin/oxytocin-related signaling regulates gustatory associative learning in C. elegans. Science 338, 543-545. doi: 10.1126/science. 1226860

Boggess, R. K., and Martin, B. R. (1975). Copper(II) chelation by Dopa, epinephrine, and other catechols. J. Am. Chem. Soc. 97, 3076-3080. doi: $10.1021 / \mathrm{ja00844a026}$

Boole, G. (1853). The Laws of Thought. The Mathematical Theories of Logic and Probabilities. Project Guteberg (EBook \#15114). Released: Feb. 2005.

Brady, S., Albers, W. R., and Price, D. (2011). Basic Neurochemistry: Principles of Molecular, Cellular, and Medical Neurobiology, 8th Edn. New York, NY: Elsevier Science.

Buhot, M. C., Martin, S., and Segu, L. (2000). Role of serotonin in memory impairment. Ann. Med. 32, 210-221. doi: 10.3109/07853890008998828

Burbach, J. P. H. (2010). Neuropeptides from concept to online database: www.neuropeptides.nl. Eur. J. Pharmacol. 626, 27-48. doi: 10.1016/j.ejphar.2009.10.015

Chandra, S. V., Shukla, G. S., Srivastava, R. S., and Gupta, S. K. (1980). Combined effect of metals on biogenic amines and their distribution in the brain of mice. Arch. Environ. Contam. Toxicol. 9, 79-85. doi: 10.1007/BF01055501

Coffman, F. D., and Dunn, M. F. (1988). Insulin-metal ion interactions: the binding of divalent cations $\left(\mathrm{Ca}^{+2}, \mathrm{Co}^{+2}, \mathrm{Zn}^{+2}\right)$ to insulin hexamers and tetramers and the assembly of insulin hexamers. Biochemistry 27, 6179-6187. doi: 10.1021/bi00416a053

Colburn, R. W., and Maas, J. W. (1965). Adenosine triphosphate-metalnorepinephrine ternary complexes and catecholamine binding. Nature 208, 37-46. doi: 10.1038/208037a0

DeFelipe, J. (2011). The evolution of the brain, the human nature of cortical circuits, and intellectual creativity. Front. Neuroanat. 5:29. doi: 10.3389/fnana.2011.00029

Delgado, R., Vergara, C., and Wolff, D. (2006). Divalent cations as modulators of neuronal excitability: emphasis on copper and zinc. Biol. Res. 39, 173-182. doi: 10.4067/S0716-97602006000100019
Dere, E., Zlomuzica, A., De Souza Silva, M. A., Ruocco, L. A., Sadile, A. G., and Huston, J. P. (2010). Neuronal histamine and the interplay of memory, reinforcement and emotions. Behav. Brain Res. 215, 209-220. doi: 10.1016/j.bbr.2009.12.045

Emmons, S. W. (2012). The mood of a worm. Science 338, 475-476. doi: $10.1126 /$ science. 1230251

Flood, J. F., Baker, M. L., and Davis, J. L. (1990). Modulation of memory processing by glutamic acid receptor agonists and antagonists. Brain Res. 521, 197-202. doi: 10.1016/0006-8993(90)91543-P

García, C. R., Angelé-Martínez, C., Wilkes, J. A., Wang, H. C., Battin, E. E., and Brumaghim, J. L. (2012). Prevention of iron- and copper-mediated DNA damage by catecholamine and amino acid neurotransmitters, L-DOPA, and curcumin: metal binding as a general antioxidant mechanism. Dalton Trans. 41, 6458-6467. doi: 10.1039/c2dt30060e

Garcia-Lopez1, P., Garcia-Marin, V., and Freire, M. (2010). The histological slides and drawings of Cajal. Front. Neuroanat. 4, 1-16. doi: 10.3389/neuro.05.009. 2010

Garrison, J. L., Macosko, E. Z., Bernstein, S., Pokala, N., Albrecht, D. R., and Bargmann, C. I. (2012). Oxytocin/vasopressin-related peptides have an ancient role in reproductive behavior. Science 338, 540-543. doi: 10.1126/science. 1226201

Goyal, R. K., and Chaudhury, A. (2013). Structure activity relationship of synaptic and junctional neurotransmission. Auton. Neurosci. 176, 11-31. doi: 10.1016/j.autneu.2013.02.012

Guastella, A. J., Einfeld, E. L., Gray, K., Rinehart, N., Tonge, B., Lambert, T. J., et al. (2010). Intranasal oxytocin improves emotion recognition for youth with autism spectrum disorders. Biol. Psychiatry 67, 692-594. doi: 10.1016/j.biopsych.2009.09.020

Hirano, Y., Masuda, T., Naganos, S., Matsuno, M., Ueno, K., Miyashita, T., et al. (2013). Fasting launches CRTC to facilitate long-term memory formation in drosophila. Science 339, 443-446. doi: 10.1126/science. 1227170

Hughes, K. R., and Zubek, J. P. (1956). Effect of glutamic acid on the learning ability of bright and dull rats: I. Administration during infancy. Can. J. Psychol. 10, 132-138. doi: 10.1037/h0083678

James, W. (1884). What is an Emotion? MIND 9, 188-206. doi: 10.1093/mind/osIX.34.188

Jarrell, T. A., Wang, Y., Bloniarz, A. E, Brittin, C. A., Xu, M., Thomson, J. N., et al. (2012). The connectome of a decision-making neural network. Science 337, 437-446. doi: 10.1126/science. 1221762

Jefferys, J. G. (1995). Nonsynaptic modulation of neuronal activity in the brain: electric currents and extracellular ions. Physiol. Rev. 75, 689-723.

Jolles, J. (1983). "Vasopressin-like peptides and the treatment off memory disorders in man," in Neurohypophys: Structure, Function and Control, Progress in Brain Research, Vol. 60, eds B. A. Cross and G. Leng (Amsterdam: Elsevier Science Publishers), 169-182. doi: 10.1016/S0079-6123(08)64384-8

Kaler, S. G. (2011). ATP7A-related copper transport diseases. Nat. Rev. Neurol. 7, 15-29. doi: 10.1038/nrneurol.2010.180

Kandel, E. R. (2009). The biology of memory: a forty-year perspective. J. Neurosci. 29, 12748-12756. doi: 10.1523/JNEUROSCI.3958-09.2009

Kroval, I. A., Gamez, P., Belle, C., Seleczi, K., and Reedjik, J. (2006). Synthetic models of the active site of catechol oxidase: Mechanistic studies. J. Chem. Soc. Rec. 35, 814-840. doi: 10.1039/b516250p

Langer, S. (1967). "Philosophical sketches: a study of the human mind in relation to feeling, explored through art, language, and symbol," in Barnes and Noble Books 1 st $B$ and $N$ edition, 1-487.

Lehn, J. M. (2002). Toward complex matter: supramolecular chemistry and self-organization. Proc. Natl. Acad. Sci. U.S.A. 99, 5201-5206. doi: 10.1073/pnas.072065599

Lehn, J. M. (2012). "Constitutional dynamic chemistry: bridge from supramolecular chemistry to adaptive chemistry," in Constitutional Dynamic Chemistry, ed A. Barboiu (Berlin: Springer), 1-32.

Lesburguères, E., Gobbo, O. L., Alaux-Cantin, S., Hambucken, A., Trifilieff, P., and Bontempi, B. (2011). Early tagging of cortical networks is required for the formation of enduring associative memory. Science 331, 924-930. doi: 10.1126/science. 1196164

Ludlam, C. A., Peake, I. R., Allen, N., Davies, B. L., Furlong, R. A., and Bloom, A. L. (1980). Factor VIII and fibrinolytic response to deamino-8-D-argenine vasopressin in normal subjects and dissociate response in some patients with 
Haemophilia and von Willebrand's disease. Br. J. Haematol. 45, 499-511. doi: 10.1111/j.1365-2141.1980.tb07169.x

Ma, C., Su, L., Seven, A. B., Xu, Y., and Rizo, J. (2013). Reconstitution of the vital functions of Munc18 and Munc13 in neurotransmitter release. Science 339, 421-425. doi: $10.1126 /$ science. 1230473

Marazziti, D., Dell'Osso, B., Baroni, S., Mungai, F., Catena, M., Rucci, P., et al. (2006). A relationship between oxytocin and anxiety of romantic attachment. Clin. Pract. Epidemiol. Ment. Health 2:28. doi: 10.1186/1745-0179-2-28

Marx, G. (1984). "Albumin and bilirubin: a conceptual analysis of binding sites and structures," in Rev. Biochem. Toxicology, eds E. Hodgson, J. R. Bend, and R. M. Philpot (New York, NY; Amsterdam: Elsevier), 65-95.

Marx, G., and Gilon, C. (2012). The molecular basis of memory. ACS Chem. Neurosci. 3, 633-642. doi: 10.1021/cn300097b

Marx, G., and Gilon, C. (2013). The molecular basis of memory. Pt 2. The chemistry of the tripartite mechanism. ACS Chem. Neurosci. 4, 983-993. doi: $10.1021 / \mathrm{cn} 300237 \mathrm{r}$

Meshulam, M., Winter, E., Ben-Shakhar, G., and Aharon, I. (2011). Rational emotions. Soc. Neurosci. 7, 1-7. doi: 10.1080/17470919.2011.559124

Murtya, V. P, Ritcheya, M., Adcocka, R., and LaBara, K. S. (2011). fMRI studies of successful emotional memory encoding: a quantitative meta-analysis. Neuropsychologia 49, 695-705. doi: 10.1016/j.neuropsychologia.2011.02.031

Neumann, I. D. (2007). Oxytocin: the neuropeptide of love reveals some of its secrets. Cell Metab. 5, 231-233. doi: 10.1016/j.cmet.2007.03.008

Ortega, R., Cloetens, P., Deve's, G., Carmona, A., and Bohic, S. (2007). Iron storage within dopamine neuro-vesicles revealed by chemical nano-imaging. PLoS ONE 2:e925. doi: 10.1371/journal.pone.0000925

Paoletti, P., Pergnano, A. M., Barbour, B., and Casado, M. (2009). Zinc at glutamatergic synapses. Neuroscience 158, 126-136. doi: 10.1016/j.neuroscience. 2008.01.061

Pitt, J., Thorner, M., Brautigan, D., Larner, J., and Klein, W. L. (2013). Protection against the synaptic targeting and toxicity of Alzheimer's-associated $A \beta$ oligomers by insulin mimetic chiro-inositols. FASEB J. 27, 199-207. doi: 10.1096/fj.12-211896

Pollock, J. (1997). "Painting: \# 3 tiger," in Jackson Pollock Paintings, ed P. Monsel Paris: Cercle D'Art.

Reith, M. E. (2002). Neurotransmitter Transporters: Structure, Function, and Regulation, 2nd Edn. New York, NY: Springer-Verlag.

Romanes, G. J. (1883). "Mental evolution in animals," in With Posthumous Essay on Instinct by Charles Darwin (London: Kegan, Paul, Trench and Co, Nabu Public Domain Reprints), 1-411.

Sadiq, S., Ghazala, Z., Chowdhury, A., and Büsselberg, D. (2012). Metal toxicity at the synapse: presynaptic, postsynaptic, and long-term effects. J. Toxicol. 42:132671. doi: 10.1155/2012/132671

Shaik, S. (2003). Chemistry—A central pillar of human culture. Angew. Chem. Int. Ed. 42, 3208-3215. doi: 10.1002/anie.200330038

Siegel, G. J., Albers, R. W., and Price, D. L. (2005). Basic Neurochemistry, 7th Edn. Molecular, Cellular and Medical Aspects. Philadelphia, PA: Lippincott-Raven.

Sigel, H., and Martin, R. B. (1982). Coordinating properties of the amide bond: stability and structure of metal ion complexes of peptides and related ligands. Chem. Rev. 82, 385-426. doi: 10.1021/cr00050a003

Squire, L., and Kandel, E. (2008). Memory: From Mind to Molecules, 2nd Edn. New York, NY: Roberts and Company Publishers.

Strausfeld, N. J., and Hirth, F. (2013). Deep homology of arthropod central complex and vertebrate basal ganglia. Science 340, 157-163. doi: 10.1126/science. 1231828

Syková, E., and Nicholson, C. (2008). Diffusion in brain extracellular space. Physiol. Rev. 88, 1277-1340. doi: 10.1152/physrev.00027.2007
Trueta, C., and De-Miguel, F. F. (2012). Extrasynaptic exocytosis and its mechanisms: a source of molecules mediating volume transmission in the nervous system. Front. Physiol. 3:319. doi: 10.3389/fphys.2012. 00319

Turing, A. M. (1950). Computing machinery and intelligence. Mind (New Series) 59, 433-460. doi: 10.1093/mind/LIX.236.433

van der Burgt, Y. E., Palmblad, M., Dalebout, H., Heeren, R. M., and Deelder, A. M. (2009). Electron capture dissociation of peptide hormone changes upon opening of the tocin ring and complexation with transition metal cations. Rapid Commun. Mass Spectrom. 23, 31-38. doi: 10.1002/ rcm.3849

Velez-Pardo, C., Jimenez del Rio, M., Ebinger, G., and Vauquelin, G. (1995). Manganese and copper promote the binding of dopamine to "serotonin binding proteins" in bovine frontal cortex. Neurochem. Int. 26, 615-622. doi: 10.1016/0197-0186(94)00163-O

Vizi, E. S. (2013). Role of high-affinity receptors and membrane transporters in nonsynaptic communication and drug action in the central nervous system. Pharmacol. Rev. 52, 63-89.

Vizi, E. S., Fekete, A., and Karoly, R. (2010). Mike A. Non-synaptic receptors and transporters involved in brain functions and targets of drug treatment. $\mathrm{Br}$. J. Pharmacol. 160, 785-809. doi: 10.1111/j.1476-5381.2009.00624.x

White, J. M., and Rumbold, G. R. (1988). Behavioural effects of histamine and its antagonists: a review. Psychopharmacology 95, 1-14. doi: 10.1007/BF002 12757

Wright, G. A., Baker, D., Palmer, M. J., Stabler, D., Mustard, J. D., Power, E., et al. (2013). Caffeine in floral nectar enhances a pollinator's memory of reward. Science 339, 1202-1204. doi: 10.1126/science. 1228806

Wu, L. J., Leenders, A. G., Cooperman, S., Meyron-Holtz, E., Smith, S., Land, W., et al. (2004). Expression of the iron transporter ferroportin in synaptic vesicles and the blood-brain barrier. Brain Res. 1001, 108-117. doi: 10.1016/j.brainres.2003.10.066

Wyttenbach, T., Liu, D., and Bowers, M. T. (2008). Interactions of the hormone oxytocin with divalent metal ions. J. Am. Chem. Soc. 130, 5993-6000. doi: $10.1021 /$ ja 8002342

Yanagita, T., Nemoto, T., Satoh, S., Yoshikawa, N., Maruta, T., Shiraishi, S., et al. (2013). "Neuronal insulin receptor signaling: a potential target for the treatment of cognitive and mood disorders," in Mental and Behavioral Disorders and Diseases of the Nervous System, INTECH Open Access, Chapter 11, ed Nese Kocabasoglu (Rijeka: InTech), 263-287. doi: 10.5772/54389. ISBN: 978-953-510959-4

Conflict of Interest Statement: The authors declare that the research was conducted in the absence of any commercial or financial relationships that could be construed as a potential conflict of interest.

Received: 28 November 2013; accepted: 17 March 2014; published online: 07 April 2014.

Citation: Marx G and Gilon C (2014) The molecular basis of memory. Part 3: tagging with "emotive" neurotransmitters. Front. Aging Neurosci. 6:58. doi: 10.3389/fnagi. 2014.00058

This article was submitted to the journal Frontiers in Aging Neuroscience.

Copyright () 2014 Marx and Gilon. This is an open-access article distributed under the terms of the Creative Commons Attribution License (CC BY). The use, distribution or reproduction in other forums is permitted, provided the original author $(s)$ or licensor are credited and that the original publication in this journal is cited, in accordance with accepted academic practice. No use, distribution or reproduction is permitted which does not comply with these terms. 